\title{
PERANCANGAN SISTEM PENGONTROLAN TEMPERATUR PADA ALAT PENETAS TELUR OTOMATIS
}

\author{
Mardian Peslinof*, M. Ficky Afrianto, Suparman, Samsidar \\ Fisika, Fakultas Sains Dan Teknologi, Universitas Jambi, Jl. Jambi-Ma.Bulian KM 15, Jambi, 36361, Indonesia \\ "e-mail: mardianpeslinof@gmail.com
}

\begin{abstract}
ABSTRAK
Telah dilakukan perancangan sistem pengontrolan temperatur pada alat penetas telur otomatis. Cara kerja dari sistem ini yaitu apabila sistem ini dihidupkan maka lampu pijar sebagai sumber pemanas akan menyala dan sensor DHT11 akan mendeteksi temperatur pada alat penetas, apabila temperatur yang terukur telah mencapai temperatur yang dinginkan maka lampu akan mati. Agar temperatur pada alat penetas merata, maka digunakan 2 buah kipas. Kipas yang pertama arah nya kedalam yang berfungsi untuk menyebarkan panas, dan kipas yang kedua arahnya keluar yang berfungsi untuk membuang panas ketika temperatur yang diukur berlebih. Untuk mengatur sistem pada alat penetas ini sesuai dengan cara kerja yang diinginkan maka ditanamkan program pada arduino nano yang hasil nya akan ditampilkan pada LCD. Dari hasil pengujian, kestabilan sistem nilainya berkisar antara 370C dan 400C dari temperatur yang ditetapkan yaitu $380 \mathrm{C}$. Persentase ketepatan rata-rata dari sistem adalah 99,99\%. Ketelitian rata-rata dari sistem pengontrolan adalah 0,9975.
\end{abstract}

Kata Kunci : Pengontrolan; Temperatur; DHT11; Penetas telur otomatis.

\section{ABSTRACT}

[Title: Design Of Temperature Control System On Automatic Egg Incubators] A temperature control system has been designed in the automatic egg incubator. This system worked when the system turned on then the incandescen lamp as a heating source will light up and the DHT11 sensor will detect the temperature of the incubator, when the measured temperature has reached the disposed temperature then the lamp will turn off. This would make the temperature of incubator evenly distributed. In this system there are two fans. The first one was in the direction that serves to spread heat, and the second fan was out which function to dissipate heat when the measured temperature was excessive. To set the system on the incubator also be equipped by the program in Arduino Uno and the results of the program will displayed on the LCD. The results of the test showed the stability of the system ranges betweet $37^{\circ} \mathrm{C}$ and $40^{\circ} \mathrm{C}$ from the set temperature of $38^{\circ} \mathrm{C}$. the percentage of the average accuracy of the system was $99,99 \%$. The average accuracy of the control system was 0,9975 .

Keywords: Control; Temperature; DHT11; Automatic egg incubator

\section{PENDAHULUAN}

Alat penetas telur merupakan salah satu aplikasi dari perkembangan ilmu dan teknologi. Alat penetas telur ini dibuat dengan cara mencontoh proses pengereman secara alamiah yang dilakukan induk ayam. Salah satu faktor penting pada alat penetas telur adalah suhu. Suhu berperan penting untuk menentukan kesuksesan hasil tetasan telur. Suhu ideal untuk penetasan telur ayam berkisar antara $36^{\circ} \mathrm{C}-40^{\circ} \mathrm{C}$ atau dapat diseragamkan pada suhu antara $37^{\circ} \mathrm{C}-39^{\circ} \mathrm{C}$ (Larasati, 2019). Pada umumnya mesin penetas yang ada sekarang ini masih menggunakan yang manual dan suhu nya kurang merata dimana hanya bergantung pada panas yang dihasilkan oleh lampu pijar. Penetasan telur jika dilakukan secara manual maka harus melakukan pemindahan telur secara manual, memantau keadaan suhu yang ditetapkan perjam atau mensetting suhu yang diharapkan dengan melakukan percobaan berkali-kali. Oleh karena itu diperlukan dukungan teknologi yang dapat mempermudah dalam penetasan telur, yaitu dengan menggunakan alat penetas telur otomatis. Dengan menggunakan alat penetas telur yang otomatis maka peternak hanya memerlukan waktu sekali saja untuk meletakkan telur dan alat secara otomatis bekerja sampai telur menetas. Alat penetas telur otomatis seharusnya bisa menetaskan telur secara maksimal. Agar bisa mengerami telur secara maksimal maka suhu pada alat tersebut harus diatur sesuai dengan suhu penetasan apabila dilakukan secara alamiah. Di dalam tempat penetasan telur, suhu harus tersebar secara merata agar semua telur akan mendapatkan suhu yang sama (Nusyirwan, 2019). Supaya panas 
pada alat penetas telur mempunyai suhu yang merata, maka perlu diperhatika posisi pemanas dan pendingin pada alat. Posisi pemanas dengan pendingin atau untuk sirkulasi udara sangat berpengaruh pada mekanisme pendistribusian suhu di dalam ruangan supaya merata dan stabil (Setyaningsih, 2019).

Beberapa penelitian telah dilakukan terhadap pengaturan suhu pada alat penetas telur otomatis. Dini ismawati membuat alat penetas telur menggunakan model kendali fuzzy, penelitian ini fokus pada pengaruh dari jumlah membership function yang digunakan untuk kendali suhu ruangan alat penetas. Aktuator yang digunakan adalah kipas yang berfungsi sebagai pendingin dan lampu sebagai pemanas. Pada penelitian ini posisi aktuator pemanas dan pendingin tidak di perhatikan dan posisi sensor suhu yang digunakan berada dibawah pemanas (Ismawati, 2017). Pada penelitian yang dilakukan Rataq yaitu untuk menjaga suhu didalam mesin penetas telur tetap stabil sesuai dengan temperatur yang dibutuhkan pada proses penetasan. Mengunakan bahasa pemograman C dan mempergunakan sensor suhu yang akan mendeteksi suhu didalam inkubator. Apabila suhu mencapai suhu dibawah 38,30C, maka mikrokontroller akan menerikan perintah kepada mesin pengerak, dan begitu juga sebaliknya apabila suhu berada diatas suhu maksimal 40.50C (Ratang, 2013). Penelitian yang dilakukan Laksono menjelaskan sebuah aplikasi sistem pengendalian suhu dengan sistem putar (turning) pada mesin penetas telur sehingga telur dapat menetas secara bersamaan. Sistem putar ini bertujuan untuk menghindari embrio yang menempel pada kulit telur. Mikrokontroller akan mendeteksi suhu untuk mengatur kerja dari lampu pijar sebagai penghasil panas dan kipas untuk mengeluarkan panas apabila sudah diatas suhu maksimal (Laksono, 2016)

Pada penelitian ini dibuat sebuah alat penetas telur yang bertujuan untuk menstabilkan dan menyebarkan suhu secara merata. Pengaturan suhu ini dilakukan dengan cara melakukan pengontrolan terhadap temperatur secara otomatis pada sistem. Pengontrolan temperatur menggunakan sensor DHT11 dan pemanas dari lampu pijar serta kipas angin. Untuk mengatur sistem pada alat penetas ini sesuai dengan cara kerja yang diinginkan maka ditanamkan program pada arduino nano yang hasil nya akan ditampilkan pada LCD.

\section{METODE PENELITIAN}

Dalam melaksanakan penelitian ini peralatan yang digunakan terdiri dari multimeter digital, termometer digital, dan stopwatch. Multimeter digital digunakan untuk mengukur nilai komponen. Termometer digital digunakan sebagai alat ukur standar mengukur teremperatur. Stopwatch dipakai untuk menentukan waktu. Bahan yang digunakan yaitu adalah wadah penetas telur, lampu pijar, relay, sensor DHT11, kipas, dan Arduino nano. .

Variabel penelitian adalah segala sesuatu yang akan menjadi objek penelitian atau faktor-faktor yang berperan penting dalam peristiwa atau gejala yang akan diteliti. Variabel penelitian ini terdiri dari tiga variabel yaitu variabel bebas, variabel terikat dan variabel kontrol. Variabel bebasnya berupa temperatur, sedangkan variabel terikat adalah Lampu pijar dan kipas. Untuk variabel kontrol yaitu nilai temperatur yang terukur oleh DHT11

Prosedur yang dilakukan dalam perancangan ini yaitu membuat alat penetas telur otomatis kemudian melakukan pengontrolan temperatur dan mengambil data ketepatan, ketelitian, dan kestabilan dari sistem. Secara umum blok diagram sistem secara keseluruhan seperti Gambar 1.

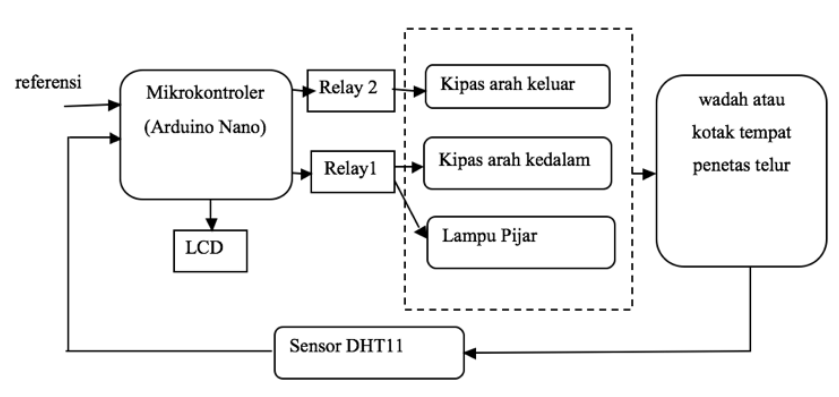

Gambar 1. Desain Sistem Pengontrolan

Gambar 1 memperlihatkan desain sistem pengontrolan temperatur alat penetas telur otomatis. Pengontrolan temperatur diatur dengan menggunakan program yang ditanamkan pada Arduino Nano dengan memasukkan referensi atau nilai temperatur yang diinginkan. Apabila sistem dihidupkan maka relay 1 akan $\mathrm{ON}$, dimana lampu pijar dan kipas arah kedalam akan hidup. Jika sistem telah mencapai temperstur referensi maka relay 1 akan OFF dan relay 2 akan ON, dan apabila temperatur telah melebihi nilai referensi maka relay 2 akan OFF dan relay 1 akan ON. Temperatur yang dibaca pada Arduino nano dideteksi oleh sensor DHT11 yang hasilnya ditampilkan pada LCD. Perancangan dari sistem pengontrolan ini terdiri dari perancangan perangkat keras dan perancangan perangkat lunak. Perangkat lunak dari sistem pengontrolan temperatur ini sudah tergambar dari diagram pada Gambar 1. Jadi program yang dibuat mengikuti desain sistem pengontrolan. Perancangan 
perangkat keras dari sistem dibuat seperti kotak, yang detailnya seperti Gambar 2.

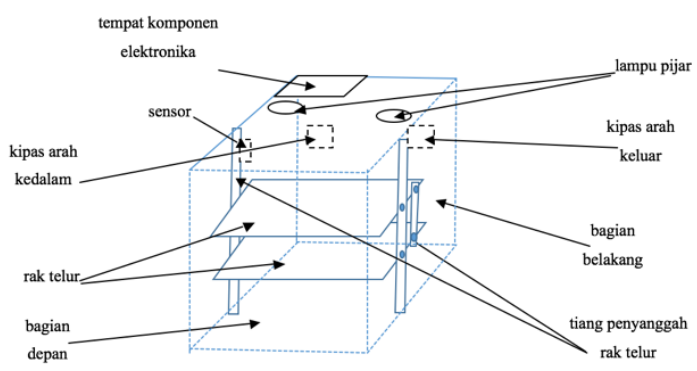

Gambar 2. Rancangan Perangkat keras sistem

Gambar 2 memperlihatkan rancangan dari perangkat keras sistem. Rancangan perangkat keras menggambarkan bentuk dari alat penetas telur yang dibuat. Alat penetas telur ini dibuat dua tingkat yang bertumpu pada tiang penyanggah pada dinding samping kotak. Sebagai sumber pemanas adalah dua buah lampu pijar yang terletak pada bagian atas. Pada bagian belakang terdapat dua buah kipas, dimana kipas yang pertama arahnya kedalam dan kipas kedua arahnya keluar. Pada bagian atas terdapat tempat komponen elektronika, sedangkan sensor terdapat didalam kotak yaitu pada tiang penyanggah rak.

\section{HASIL DAN PEMBAHASAN}

Alat yang sudah dibuat dengan sedemikian rupa disusun dan dirangkai dengan kebutuhan yang ada. Alat penetas telur terbuat dari triplek dengan ukuran $70 \times 40 \times 50 \mathrm{~cm}$. Alat penetas telur ini dapat menetaskan telur sebanyak 120 butir telur, dengan rak telur yang dibuat dua tingkat. Bentuk alat penetas telur otomatis yang dilakukan pengontrolan temperatur seperti Gambar 3.

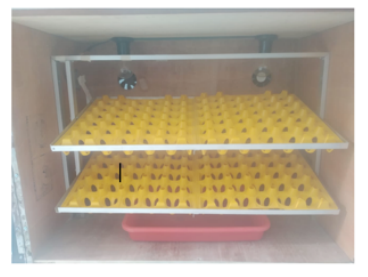

(a)

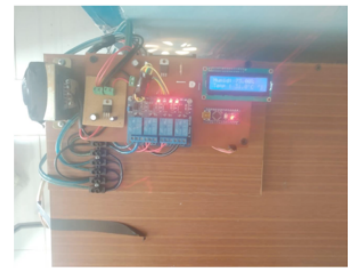

(b)
Gambar 3. Sistem Pengontrolan Temperatur Pada Alat Penetas Telur

Gambar 3 memperlihatkan hasil dari rancangan sistem pengontrolan temperatur pada alat penetas telur. Alat Penetas telur ini berbentuk kotak yang terbuat dari bahan triplek. Pada Gambar (a) terlihat kondisi didalam wadah penetas telur. Di dalam kotak itu ad arak telur, dimana rak telur ini terdiri dari dua tingkat dengan kapasitas 120 butir telur. Pada dinding sebelah atas terdapat dua buah lampu pijar sebagai sumber pemanas, dan pada dinding bagian belakang terdapat dua buah kipas yang arah kipas nya berbeda. Wadah tempat air untuk menjaga kelembaban ruangan terdapat pada bagian bawah. Sensor DHT11 ditempatkan pada tiang penyangga rak telur. Pada Gambar 3 (b), yaitu pada bagian atas luar dari pada ditempatkan komponen elktronika dari sistem. Rangkaian komponen elektronika pada sistem ini secara umum terdiri dari rangkaian catu daya, relay, Arduino nano, dan LCD.

Alat penetas telur otomatis. Dimana pada alat tersebut terdapat suatu sistem untuk pengontrolan temperatur. Pengontrolan temperatur dilakukan oleh sensor DHT11 dan heater. Wadah penetas telur dipanaskan oleh heater. Heater akan mati apabila panas dalam wadah telah mencapai set poin yang diinginkan yaitu 380C. Heater diletakkan di luar dengan wadah tertutup yang terhubung kedalam wadah. Kipas akan menyerap panas dari heater dan menyebarkan kedalam wadah.

Apabila sistem dihidupkan maka bola lampu dan kipas akan hidup. Bola lampu berfungsi sebagai sumber pemanas, sedangkan kipas berfunsi untuk menyebarkan panas. Panas yang disebarkan oleh kipas pada ruangan wadah akan menyebabkan perpindahan panas. Perpindahan panas merupakan perpindahan energi dalam bentuk panas yang terjadi karena adanya perbedaan suhu di antara benda atau material. Dalam proses perpindahan energi tersebut tentu ada kecepatan perpindahan panas yang terjadi, atau yang lebih dikenal dengan laju perpindahan panas. Ada dua bentuk mekanisme perpindahan panas pada sistem ini yaitu perpindahan secara konduksi dan perpindahan secara konveksi.

Konduksi, merupakan perpindahan panas dari partikel yang lebih berenergi ke partikel yang kurang berenergi yang saling berdekatan dari sebuah bahan karena interaksi antara partikel tersebut. Rumusan persamaan untuk laju perpindahan panas secara konduksi adalah:

$$
q=k A \frac{T}{x}(W)
$$

dengan q sebagai laju perpindahan panas konduksi, $\partial \mathrm{T} / \partial \mathrm{x}$ sebagai gradient suhu ke arah perpindahan panas, $\mathrm{k}$ sebagai konduktivitas atau kehantaran termal benda dengan tanda minus menunjukkan aliran kalor ke tempat yang bertemperatur lebih rendah, dan A sebagai luas permukaan yang mengalami perpindahan panas tersebut

Konveksi, merupakan perpindahan panas antara permukaan solid dan berdekatan dengan 
fluida yang bergerak atau mengalir, dan itu melibatkan pengaruh konduksi dan aliran fluida. Rumusan persamaan untuk meramalkan laju perpindahan panas secara konveksi adalah:

$$
q=h A(T s \quad T)(W)
$$

dengan q sebagai laju perpindahan panas konveksi, h sebagai koefisien perpindahan-kalor konveksi, A sebagai luas permukaan yang mengalami perpindahan panas, Ts sebagai temperatur permukaan benda solid yang dilalui fluida yang mengalir, T $\infty$ sebagai temperatur fluida yang mengalir berdekatan dengan permukaan benda solid.

Penyelidikan yang dilakukan pada sistem pengontrolan temperatur pada alat penetas telur ini yaitu menyelediki ketepatan, ketelitian dan kestabilan dari sistem. Ketepatan (accuracy) merupakan tingkat kesesuian atau dekatnya suatu hasil pengukuran terhadap harga sebenarnya. Ketepatan dari sistem dapat ditentukan dari persentase kesalahan antara nilai aktual dengan nilai yang terlihat. Persentase kesalahan dapat ditentukan dari persamaan (3).

Persentase kesalahan $=\frac{Y n \quad X n}{Y n} \cdot 100 \%$

dimana; $\quad \mathrm{Yn}=$ Nilai sebenarnya dan $\mathrm{Xn}=$ Nilai yang terbaca pada alat ukur. Jadi pada sistem kita lakukan pengukuran langsung terhadap temperatur yang divariasikan dan membandingkan temperatur yang terbaca pada LCD dengan hasil pada termomemeter digital. Data yang didapatkan seperti Tabel 1.

Tabel 1. Ketepatan Sistem Pengontrolan

\begin{tabular}{|c|c|c|c|}
\hline No & $\begin{array}{c}\text { Temperatur } \\
\text { Pada alat }\left({ }^{\circ} \mathrm{C}\right)\end{array}$ & $\begin{array}{c}\text { Tinggi Pada } \\
\text { Termometer } \\
\left({ }^{\circ} \mathrm{C}\right)\end{array}$ & Ketepatan (\%) \\
\hline 1 & 30 & 30,7 & 99,98 \\
\hline 2 & 32 & 32,5 & 99,98 \\
\hline 3 & 34 & 34,2 & 99,99 \\
\hline 4 & 36 & 36,3 & 99,99 \\
\hline 5 & 38 & 38,3 & 99,99 \\
\hline 6 & 40 & 40,8 & 99,98 \\
\hline 7 & 42 & 42,5 & 99,99 \\
\hline 8 & 44 & 44,6 & 99,99 \\
\hline 9 & 46 & 46,3 & 99,99 \\
\hline 10 & 48 & 48,5 & 99,99 \\
\hline \multicolumn{4}{|c|}{ Persentase ketepatan rata-rata } \\
\hline
\end{tabular}

Dari tabel 1 didapatkan data ketepatan dari sistem. Dari data yang ada maka didapatkan kesalahan rata-rata dari sitem adalah 0,01\%.
Persentase ketepatan rata-rata yang didapatkan adalah 99,99\%. Dari hasil persentase rata-rata tersebut maka dikan sistem ini memiliki nilai ketepatan yang sangat baik.

Ketelitian yaitu tingkat kesamaan data yang dilakukan secara berulang. Ketelitian dapat diekspresikan dalam bentuk matematika sebagai berikut:

$$
\operatorname{Pr} \text { ecision }=1\left|\frac{X n \quad \bar{X} n}{X n}\right|
$$

dimana; Xn = nilai dari pengukuran ke $\mathrm{n}$ dan $\mathrm{Xn}=$ rata-rata dari set $n$ pengukuran. Ketelitian dari sistem pengontrolan ditentukan dengan melakukan pengukuran secara berulang sebanyak 10 kali dengan beberapa variasi temperaturnya Berdasarkan data pengukuran berulang diperoleh hasil analitis statistik seperti pada Tabel 2.

Tabel 2. Data Ketelitian Pengontrolan

\begin{tabular}{|c|c|c|c|c|}
\hline NO & Temperatur $\left({ }^{\circ} \mathrm{C}\right)$ & $\begin{array}{c}\text { Jumlah temperatur } \\
\left({ }^{\circ} \mathrm{C}\right)\end{array}$ & $\begin{array}{c}\text { Temperatur } \\
\text { rata-rata }\left({ }^{\circ} \mathrm{C}\right)\end{array}$ & Ketelitian \\
\hline 1 & 30 & 300,1 & 30,1 & 0,997 \\
\hline 2 & 35 & 102,4 & 34,7 & 0,992 \\
\hline 3 & 40 & 152,5 & 39,7 & 0,991 \\
\hline 4 & 45 & 202,6 & 44,7 & 0,993 \\
\hline \multicolumn{4}{|c|}{ Rata-rata ketelitian } & 0,9975 \\
\hline
\end{tabular}

Dari hasil analisis data pada Tabel 2 dapat dijelaskan bahwa tingkat ketelitian dari sistem pengontrolan temperatur pada alat penetas telur berkisar antara 0,9974 sampai 0,9979. Ketelitian rata-rata dari sistem pengontrolan adalah 0,9975. Kesalahan rata-rata dari ketelitian sistem pengontrolan ini adalah 0,0025. Berarti ketelitian dari sistem termasuk tinggi.

Kestabilan dari pengontrolan sistem yaitu kemampuan sistem untuk mempertahankan kondisi yang telah ditetapkan. Temperatur yang ditetapkan pada alat penetas telur ini yaitu 380C. Ketika sistem dihidupkan maka bola lampu dan kipas kedalam akan hidup, apabila sistem telah mencapai temperatur Heater akan mengontrol temperatur dengan cara mematikan heater apabila telah mencapai temperatur 380C maka bola lampu dan kipas kedalam akan mati. Waktu yang diambil untuk kestabilan sistem ini dimulai ketika sistem dalam posisi sesuai dengan temperatur yang ditetapkan yaitu 380C. Keadaan kestabilan pengontrolan sesuai waktu dapat dilihat pada Gambar 4. 


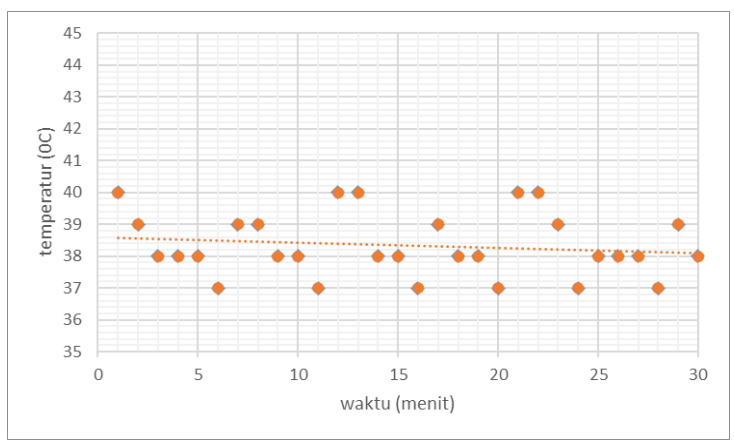

Gambar 4. Kestabilan Pengontrolan Untuk Set Poin $38^{0} \mathrm{C}$

Pada gambar 4 kestabilan temperatur berdasarkan waktu dengan set poin yang diminta yaitu 380C bervariasi antara empat nilai yaitu 370C, 380C, 390C, dan 400C. Nilai rata-rata kestabilan dalam selang waktu 5 menit selama 2 jam adalah $38,330 \mathrm{C}$. Nilai rata-rata yang hampir sama dengan set poin menandakan penyimpangan kecil, kestabilan dari sistem baik.

\section{KESIMPULAN}

Dalam perancangan sistem pengontrolan temperatur pada alat penetas telur terdiri dari perancangan perangkat keras dan perancangan perangkat lunak. Perangkat keras dari sistem mempunyai beberapa bagian yaitu kotak tempat penetasan telur dan rangkaian elektronika. Perangkat lunak dari sistem yaitu program yang ditanamkan pada Arduino nano. Desain program yang dibuat yaitu apabila sistem dihidupkan maka lampu pijar dan kipas arah kedalam akan hidup. Jika sistem telah mencapai temperatur yang ditetapkan maka lampu dan kipas arah kedalam akan mati dan kipas arah keluar akan hidup. Temperatur yang dibaca pada Arduino nano dideteksi oleh sensor DHT11 yang hasilnya ditampilkan pada LCD. Ketepatan sistem baik dengan persentase ketepatan rata-rata adalah 99,99\%. Ketelitian dari sistem juga tinggi yaitu didapatkan kesalahan rata-rata dari ketelitian sistem pengontrolan ini adalah 0,0025. Ketelitian rata-rata dari sistem pengontrolan adalah 0,9975. Kestabilan sistem dengan set point yaitu 380C bervariasi antara empat nilai yaitu 370C, 380C, 390C, dan 400C.

\section{DAFTAR PUSTAKA}

D. Nusyirwan, M. farudin, dan P. Perdana, 2019, Perancangan Purwarupa Pengatur Suhu Otomatis Pada Inkubator Penetasan Telur Ayam Menggunakan Arduino Uno dan Sensor Suhu IC LM35, Jurnal Aplikasi
Sains dan Teknologi, 3(1), 2019, page 6072

D. Ismawati, D. Syauqy, dan B. H. Prasetio. 2017. Perbandingan Jumlah Membership Dan Model FuzzyTerhadap Perubahan Suhu Pada Inkubator Penetas Telur. J. Pengemb. Teknol. Inf. dan Ilmu Komput., 1(6) 476485

I. Larasati, N. Y. Dwi Setyaningsih, and M. Iqbal, . 2019. Rancang Bangun Sistem Kendali Suhu Pada Penetas Telur Ayam Berbasis Java Menggunakan Fuzzy Logic Control. Simetris J. Tek. Mesin, Elektro dan Ilmu Komput., 10 (1) 127-134.

Laksono, A. B., Bachri, A., and Sukin. 2016. Rancang bangun otomatisasi mesin penetas telur sistem turning berbasis mikrokontroler ATMEGA 328, Jurnal Program Studi Teknik Elektro JE-Unisla, Vol 1, No 2 .

N. Y. D. Setyaningsih. 2019. Optimalisasi Posisi Heater dan Cooler Terhadap Perubahan Kondisi Suhu pada Inkubator Tetas Penetas telur, Jurnal SIMETRIS Vol. 10 No.1 April 2019

Ratag, C.C., 2013. Simulasi sistem pengontrol suhu pada mesin pentas telur berbasis mikrokontroller AT59C52, Jurnal Teknologi Informasi, 19 (2) 148-158 